\title{
EXPLAINED INFERTILITY AMONG THE COUPLE ATTENDING THE INFERTILITY UNIT OF BANGABANDHU SHEIKH MUJIB MEDICAL UNIVERSITY (BSMMU), BANGLADESH
}

\author{
SULTANA A ${ }^{1}$, TANIRA $\mathrm{S}^{2}$, ADHIKARY $\mathrm{S}^{3}, \mathrm{KEYA} \mathrm{KA}^{4}$, AKHTER $\mathrm{S}^{5}$
}

\begin{abstract}
:
Context: The causes of infertility vary from country to country among different cultural, environmental and socio economic groups. The aim of the study was to explain the causes of infertility among the couple attending infertility unit of Bangabandhu Sheikh Mujib Medical University (BSMMU), Bangladesh and to compare with previous studies of both local and abroad.

Methods: This cross sectional study was carried out between September 2007 and March 2008 at infertility unit of BSMMU Hospital, Dhaka, among 110 couples, who had tried unsuccessfully for more than one year to reproduce. The data included history, physical examination and relevant investigations for female partners and male partners.

Results: The age group of 25-30 years was the most vulnerable as they represented 52\% of primary and $51.42 \%$ of secondary infertility. Among the 110 subfertile couples, $43.63 \%$ had female factor problems; $20 \%$ were suffering from male factor problems. In $21.81 \%$ of cases both male and female were responsible. In $14.54 \%$ cases, there were no causes, and, therefore, remain unexplained infertility. Among women, primary subfertility was $68.18 \%$, secondary subfertility was $31.81 \%$ and among men, it was $79 \%$ and $21 \%$ respectively. Most of the infertile couples (43.64\%) were trying for 2-5 years. In this study, most common cause was ovarian dysfunction (33.63\%). Among them, anovulation with regular menstruation was found in $60 \%$, polycystic ovarian disease in 32\%, hyperprolactinaemia in 16\% cases. Bilateral tubal occlusion was found in $8 \%$ and pelvic adhesions in 24\% by doing laparoscopy. In addition, 10\% of patients had endometriosis. Fibroid uterus was found in 26\% cases. Among the primary subfertility cases, common causes were anovulation with regular menstruation (14.66\%) and polycystic ovarian disease (12\%). 40\% of secondary subfertility was related with menstrual regulation (MR). Among male factors, azoospermia was found in $6.36 \%$ cases, oligozoospermia in $10.9 \%$ cases, asthenozoospermia $18.18 \%$, teratozoospermia was in $6.36 \%$ cases.
\end{abstract}

Conclusion: Primary subfertility cases were more common than secondary subfertility cases. Ovarian dysfunction was the common causes of subfertility. Other factors were abnormal semen analysis, endometriosis, tubal occlusion, pelvic adhesions and fibroid uterus.

Key Words: Infertility, subfertility, eligible couple.

J Dhaka Med Coll. 2014; 23(1) : 114-20.

\section{Introduction:}

Infertility is defined as inability of an eligible couple to conceive within one year of unprotected coitus ${ }^{1}$. Now-a-days, it is common practice to begin the investigations of a couple when one year has elapsed without contraception in spite of normal coitus, especially if the woman is aged over 30 years or the man is aged over 40 years $^{1,2}$.
Approximately $10-15 \%$ of marriages prove to be as childless ${ }^{2,3}$. Infertility classified as primary infertility applies to those who have never conceived, and secondary infertility designates those who have conceived at some time in the past ${ }^{2}$.

World Health Organization (WHO) has estimated that one in every four eligible

1. Dr. Arifa Sultana, Senior Registrar, Department of Obstetrics \& Gynaecology, Apollo Hospitals, Dhaka.

2. Dr. Shaorin Tanira, Assistant Director (Health), MCH-FP Clinic, Manabik Shahajya Sangstha (MSS), Dhaka.

3. Dr. Sanchita Adhikary, Junior Consultant, Department of Obstetrics \& Gynaecology, Jessore Sadar Hospital, Jessore.

4. Dr. Kashfia Ahmed Keya, Medical Officer, Department of Obstetrics \& Gynaecology, Bangabandhu Sheikh Mujib Medical University (BSMMU), Dhaka.

5. Prof. Sayeba Akhter, Professor, Department of Obstetrics \& Gynaecology, Bangabandhu Sheikh Mujib Medical University (BSMMU), Dhaka.

For correspondence: Dr. Arifa Sultana, Senior Registrar, Department of Obstetrics \& Gynaecology, Apollo Hospitals, Dhaka. Cell Phone:+8801718515436. 
couples in developing countries had been found to be affected by infertility, when an evaluation of responses from women in Demographic and Health Surveys from 1990 was completed in collaboration with WHO in $2004^{4}$. Infertility is a global health issue, affecting approximately $8-10 \%$ of couple worldwide ${ }^{5}$. It was estimated that the rates of infertility in South Asia, as 4\% in Bangladesh, 6\% in Nepal, 5\% in Pakistan and $4 \%$ in Sri Lanka ${ }^{6}$. The causes of infertility vary from country to country and in the different cultural, environmental and socioeconomic groups ${ }^{7}$. For an example, hypothalamic -pituitary-ovarian axis disorders with anovulation are the commonest causal factors of infertility in Kuwait ${ }^{8}$. On the other hand, tubal factor infertility related to infection is more common in Africa, South America and India ${ }^{8}$.

Though the cause of infertility depends upon either husband or wife or both, sometimes wife alone is blamed in our society. In infertile couple, the aetiological factor lies in the female in about $40 \%$ of cases and in $35 \%$ cause lies in male. About 10 to $20 \%$ of cases both husband and wife are responsible for infertility and rests are unexplained ${ }^{9}$. Unexplained infertility is a term applied to a subfertile couple whose standard investigations yield normal results ${ }^{1}$. The present study is aimed to determine the explained causes of infertility among patients attending an infertility unit of a tertiary level hospital setting which may help to get some baseline data to establish the probable cause of infertility in our country through further research.

\section{Methods:}

A cross-sectional study was done in the Bangabandhu Sheikh Mujib Medical University (BSMMU) Hospital, Dhaka, between September 2007 and March 2008, on 110 infertile couple who tried unsuccessfully for more than one year, and attended BSMMU Infertility Unit for treatment. Patients were selected on the basis of following inclusion and exclusion criteria.

\section{Inclusion criteria:}

1. Infertile couples with primary or secondary infertility;

2. Patients having regular / irregular menstrual cycle;

3. Age ranging from $18-40$ years.

\section{Exclusion criteria:}

1. When husband living in abroad;

2. Trying for conception less than one year;

3. Age more than 40 years and less than 18 years for female partners.

Sample size was estimated from target population. The evaluation protocol included age, marriage duration, menstrual history, pregnancy, contraceptive and sexual history, childhood illness like mumps-orchitis and trauma to the testis. Social habits like cigarette smoking and alcohol consumption were noted. On physical examination, hirsutism, weight and height were documented for computing the body mass index (BMI). Laboratory evaluation protocol included base line investigations for all female partners, hormonal assay (FSH, LH, Prolactin, TSH, Testosterone ) in case of irregular menstruating women on any day of the cycle, serum progesterone level on the $21^{\text {st }}$ day of menstrual cycle in case of regular menstruating women, and semen analysis in case of male patients. After selection of couples, written informed consent was taken, detailed history was noted down. Then physical examination and investigations were done for both female and male partners as per protocol. Tubal evaluation was done with hysterosalpingography or diagnostic laparoscopy or dye test in those female patients whose primary investigations were normal and had already been treated with ovulation induction drugs but conception was failed some for tubal, peritoneal and uterine factors.

Data collected from the couples were recorded on a pre-designed data collection sheet for each patient. Collected data were compiled and presented in tables.

\section{Results:}

The age group of 25-30 years was the most vulnerable as they represented $52 \%$ of primary and $51.42 \%$ of secondary infertility (table-I). Among the 110 subfertile couples, $43.63 \%$ had female factor problems; $20 \%$ were suffering from male factor problems. In $21.81 \%$ of cases both male and female were responsible. In $14.54 \%$ cases, there were no causes, and, therefore, remain unexplained infertility 
(table-II). Among women, primary subfertility was $68.18 \%$, secondary subfertility was $31.81 \%$ and among men, it was $79 \%$ and $21 \%$ respectively (table-III). Most of the infertile couples $(43.64 \%)$ were trying for 2-5 years (table-IV). In this study, among women, most common cause was ovarian dysfunction (33.63\%). Among them, anovulation with regular menstruation was found in $60 \%$, polycystic ovarian disease in $32 \%$, hyperprolactinaemia in $16 \%$ cases. Bilateral tubal occlusion was found in $8 \%$ and pelvic adhesions in $24 \%$ by doing laparoscopy. In addition, $10 \%$ of patients had endometriosis. Fibroid uterus was found in $26 \%$ cases. Among the primary subfertility cases, common causes were anovulation with regular menstruation $(14.66 \%)$ and polycystic ovarian disease $(12 \%)$. $40 \%$ of secondary subfertility was related with menstrual regulation (MR). Among 110 male partners, normal semen analyses were found in $64(58.18 \%)$ and the remaining $46(41.81 \%)$ had abnormal seminal parameters e.g. azoospermia in 07 (6.36\%). oligozoospermia in $12(10.9 \%)$ and 16 patients had asthenozoospermia in $16(14.54 \%)$ and teratozoospermia in $11(10 \%)$.

The results are shown in the following tables and figures:

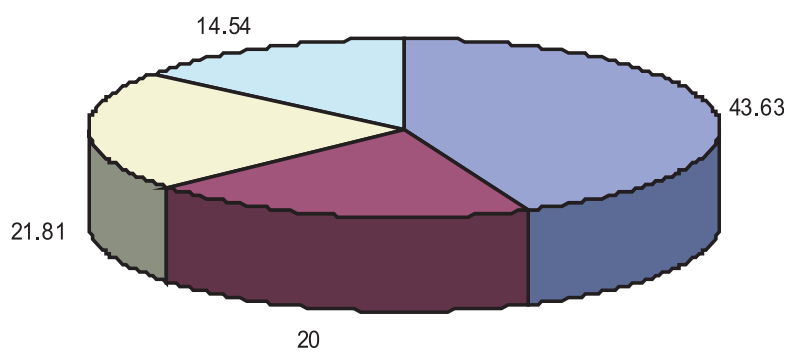

Fig. 1 : Pie diagram showing causal incidence of infertility in female and male (in percentage).

Table-I

Incidence of infertility with age distribution

\begin{tabular}{lcccc}
\hline Age group (years) & \multicolumn{2}{c}{ Primary infertility $(\mathrm{n}=75)$} & \multicolumn{2}{c}{ Secondary infertility $(\mathrm{n}=35)$} \\
& Frequency & Percentage & Frequency & Percentage \\
\hline $18-24$ & 18 & 24 & 5 & 14.28 \\
$25-30$ & 39 & 52 & 18 & 51.42 \\
$31-35$ & 12 & 16 & 9 & 25.71 \\
$36-40$ & 6 & 8 & 3 & 8.57 \\
\hline
\end{tabular}

Table-II

Types of infertility among female and male partners

\begin{tabular}{llcc}
\hline Type of infertility & & Number of patient & Percentage \\
\hline Primary & Female & 75 & 68.18 \\
& Male & 87 & 79 \\
\multirow{2}{*}{ Secondary } & Female & 35 & 31.81 \\
& Male & 23 & 21 \\
\hline
\end{tabular}

Table-III

Duration of infertility (reported to infertility unit in years after marriage)

\begin{tabular}{lcc}
\hline Duration(in years) & Number of patients & Percentage \\
\hline $1-2$ & 28 & 25.45 \\
$2-5$ & 48 & 43.64 \\
$5-10$ & 22 & 20.00 \\
$>10$ & 12 & 10.90 \\
\hline
\end{tabular}


Table-IV

Causes of primary infertility in female $(n=75)$

\begin{tabular}{|c|c|c|c|}
\hline \multicolumn{2}{|l|}{ Condition } & Number of patients & Percentage \\
\hline \multicolumn{2}{|c|}{ Anovulation with regular menstruation } & 11 & 14.66 \\
\hline \multicolumn{2}{|l|}{ Polycystic ovary } & 9 & 12 \\
\hline \multirow[t]{3}{*}{ Surgicalinterference } & Myomectomy & 3 & 8 \\
\hline & Cystectomy & 2 & \\
\hline & Ovarian drilling & 1 & \\
\hline \multicolumn{2}{|l|}{$\mathrm{D} \& \mathrm{C}$} & 3 & 4 \\
\hline \multicolumn{2}{|l|}{ Normal } & 46 & 61.33 \\
\hline
\end{tabular}

Table-V

Obstetric history of secondary infertility group $(n=35)$

\begin{tabular}{lcc}
\hline Obstetric History & Number of patients & Percentage \\
\hline Still birth & 01 & 2.85 \\
Spontaneous abortion & 10 & 28.57 \\
Menstrual regulation & 14 & 40 \\
Ectopic Pregnancy & 02 & 5.71 \\
Vaginal delivery & 05 & 14.28 \\
Caesarean section & 03 & 8.57 \\
\hline
\end{tabular}

Table-VI

Hormone assay

\begin{tabular}{|c|c|c|c|}
\hline Hormones & & Number of patients & Percentage \\
\hline \multirow[t]{2}{*}{$\overline{L H}: \mathrm{FSH}(\mathrm{n}=25)$} & Altered & 9 & 36 \\
\hline & Normal & 16 & 64 \\
\hline \multirow{2}{*}{ Serum prolactin $(n=25)$} & Raised & 4 & 16 \\
\hline & Normal & 21 & 84 \\
\hline \multirow[t]{2}{*}{ Serum testosterone $(n=12)$} & Raised & 2 & 16.7 \\
\hline & Normal & 10 & 83.3 \\
\hline \multirow[t]{2}{*}{ Serum progesterone $(n=28)$} & Altered & 11 & 39.3 \\
\hline & Normal & 17 & 60.7 \\
\hline Serum TSH $(n=25)$ & Normal & 25 & 100 \\
\hline
\end{tabular}

Table-VII

Past medical and surgical history of female $(n=110)$

\begin{tabular}{lcc}
\hline Past illness & Number of patients & Percentage \\
\hline Puerperial sepsis/ Post abortal infection & 6 & 5.45 \\
Diabetes Mellitus & 7 & 6.36 \\
Tuberculosis & 3 & 2.27 \\
Hypertension & 6 & 5.54 \\
Hypothyroidism & 4 & 3.63 \\
Pelvic Inflammatory Disease & 16 & 14.54 \\
Dilatation \& curettage & 8 & 7.27 \\
Surgical interference & 12 & 10.90 \\
None & 48 & 43.63 \\
\hline
\end{tabular}


Table-VIII

History of past illness of male $(n=110)$

\begin{tabular}{lcc}
\hline Past illness & $\begin{array}{c}\text { Number of } \\
\text { patients }\end{array}$ & Percentage \\
\hline Varicocele & 2 & 1.81 \\
Chicken pox & 5 & 4.54 \\
Diabetes Mellitus & 5 & 4.54 \\
Hypertension & 7 & 6.36 \\
Hypothyroidism & 2 & 1.81 \\
\hline
\end{tabular}

\section{Discussion:}

Fertility is affected by many different cultural, environmental and socioeconomic factors ${ }^{7,10}$. In the present study, rates of primary infertility were found much higher than that of secondary infertility, unlike evidences from previous studies $^{11-13}$. For example, overall prevalence of infertility in a rural Nigerian community reported $9.2 \%$ for primary infertility and $21.1 \%$ for secondary infertility ${ }^{12}$ and in Gabon 5.7\% for primary infertility and $20.0 \%$ for secondary infertility ${ }^{13}$. However, studies showed that $51.4 \%$ of the total had primary infertility in UK $^{14}$, while $82.48 \%$ were primarily and $17.52 \%$ secondarily infertile in South India ${ }^{9}$, which support our results.

In this study, the primary infertility was found $68.18 \%$ and secondary infertility $31.81 \%$ in females where as in males, primary infertility was $79 \%$ and secondary infertility $21 \%$. The results of the previous local studies are more or less similar to ours ${ }^{15,16}$. In the southern part of India, a study showed the incidence of female infertility $45.67 \%$ and male infertility $54.33 \%$, while $82.48 \%$ were primarily and $17.52 \%$ secondarily infertile ${ }^{9}$. In Mazandaran province of Iran, a study revealed that $50.5 \%$ of total infertility cases were due to male factors ${ }^{17}$, while it accounted for infertility in $40.2 \%$ of the couples in Kuwait ${ }^{8}$. A study conducted in the western part of Siberia found that male factors were responsible for infertility in $6.4 \%$, and female factors were responsible in $52.7 \%$ of couples ${ }^{18}$.

Infertility is an age-dependent disorder, possibly resulting from the ageing process in reproductive organs and endocrine function. Of the sociodemographic data analyzed, age most strongly correlated with the likelihood of infertility. Age distribution of population showed in primary subfertility $52 \%$ were below 30 years, while in secondary infertility, about $51 \%$ were below 30 years, which is similar to the findings of previous studies $9,15,16$. However, in UK, $26.9 \%$ of infertile couples were over 35 years ${ }^{14}$.

The present study demonstrated ovarian dysfunction as the most common cause in female infertility of which anovulatory menstrual cycle $(60 \%)$ topped the list. Anovulation is also a common factor in Kuwait $(25 \%)^{8}$ and Iran $(28.8 \%)^{17}$. Our study found women with bilateral tubal occlusion $(8 \%)$ and pelvic adhesions (24\%), for many women in developing countries especially in SubSaharan African countries suffer infertility resulting from untreated PID, a sequel of a STI or other reproductive tract infection ${ }^{3,19}$. A study done in Bangladesh showed tubal occlusion in $40.24 \%$ cases $^{16}$, while other studies done in southeastern Nigeria showed $49 \%$ bilateral tubal obstruction ${ }^{19}$ and $14.8 \%$ in Mazandaran province of Iran $^{17}$; however, all results are much higher than this study. In the present study, polycystic ovarian syndrome was detected in $32 \%$ cases. Previous local studies showed lower prevalence ${ }^{15,16}$. However, its rate is much higher in Kuwait $(52.9 \%)^{8}$. Again, endometriosis was found in $10 \%$ cases, as nearly found in other local studies ${ }^{15,16}$; however, much lower in Mongolia $(4.2 \%)^{20}$. Although endometriosis is associated with infertility, a clear causal relationship is yet to be established unless adhesive disease is found ${ }^{2}$.

Male infertility was an important issue among our patients which was mainly considered on the basis of semen parameters; azoospermia oligozoospermia, asthenozoospermia, teratozoospermia as showed similar findings in earlier studies ${ }^{16,17,19,21}$, which are more or less in agreement with the results of the present study. In this study, history of illness in males include varicocele, chicken pox, diabetes mellitus, hypertension, hypothyroidism etc. Except varicocele (2.17\%), most of them had no association with semen 
abnormality. A study done in the southeastern part of Nigeria showed history of varicocele and cryptorchidism as associated health problems in infertile males ${ }^{19}$, which is in agreement with our study. However, in the last five decades, possible declining in sperm quality and deterioration of male reproductive health have resulted wide scientific and public attention ${ }^{22}$. It may be mentioned that industrialization, environmental pollution, use of chemicals and repeated exposure to hazardous materials adversely affected reproductive health ${ }^{23}$.

In our study, $43.63 \%$ patients came with history of infertility within 5 years of their marriage, where as $30 \%$ came within 10 years. Relatively delayed attendance of subfertile couples to the infertility clinic was found in developing countries $^{9,10,19}$. Delayed treatment-seeking behaviour of infertile couples might be related to insufficient coverage and lack of specialized skills and laboratory facilities in the health services, and ineffective referral. However, one of the most significant determinants of delayed treatment seeking in developing countries seems to be poor public knowledge about infertility $9,10,21$.

Although infertility is recognized as a widespread health problem, some controversies exist regarding the prevalence of infertility among different regions and countries. They may attribute to differences in access to health care facilities, and socioeconomic, cultural and racial variations ${ }^{10,14}$.

However, in social context, childlessness was found to result in perceived role failure, with social and emotional consequences for both men and women, and often resulted in social stigmatization of the couple, particularly of the woman ${ }^{16,19,24}$. Infertility places women at risk of social and familial displacement, and women clearly bear the greatest burden of infertility ${ }^{19,24}$. Successful programmes for dealing with infertility in Bangladesh need to include both appropriate and effective sources of treatment at community level and community-based interventions to demystify the causes of infertility, so that people know why infertility occurs in both men and women and and where best to seek care ${ }^{24}$.

\section{Limitation of the study:}

It might be included in limitation of the study. The male partner of infertile couple was usually reluctant to visit the infertility clinic. Another limitation was that the male partner was selected on the basis of history and semen analysis and no physical examination was done. Studies with larger samples and longer duration are recommended to assess the accurate picture of developing countries.

\section{References:}

1. Kumar P, Malhotra N. eds. Infertility and assisted reproductive technology. In: Jeffcoate's principles of gynaecology. $7^{\text {th }}$ ed. New Delhi: Jaypee; 2008.

2. Ghadir S, Ambartsumyan G, DeCherney AH. Infertility. In: DeCherney AH, Nathan L, Laufer N, Roman AS. eds. Current diagnosis and treatment: obstetrics \& gynecology. $11^{\text {th }}$ ed. New York: McGraw-Hill; 2013.

3. Dutta DC, Konar H. Infertility. In: Text book of gynaecology: including contraception. $5^{\text {th }}$ ed. Kolkata: New Central Book Agency; 2007.

4. World Health Organization. Available from: http:/ /www.who.int/reproductive health/topics / infertility/burden/en/index.html [Accessed on September 17, 2012].

5. Inhorn MC. Global infertility and the globalization of new reproductive technologies: illustration from Egypt. Soc Sci Med 2003; 56(9): 1837-51.

6. Vaessen M. Childlessness and infecundity. WFS Comparative Studies, Series 31. Voorburg, the Netherlands: Cross National Summaries; 1984.

7. Safarinejad MR. Infertility among couples in a population-based study in Iran: prevalence and associated risk factors. Int $\mathrm{J}$ Androl 2008; 31(3): 303-14.

8. Omu AE, Al-Qattan F, Ismail AA, Al-Taher SI, AlBusiri N, Bandar A. Causal factors and management options of infertility in Kuwait. Med Principles Pract 2000; 9(2): 131-8.

9. Shamila S, Sasikala SL. Primary report on the risk factors affecting female infertility in South Indian districts of Tamil Nadu and Kerala. Indian J Community Med 2011; 36(1): 59-61.

10. Leke RJ, Oduma JA, Bassol-Mayagoitia S, Bacha AM, Grigor KM. Regional and geographical variations in infertility: effects of environmental, cultural and socioeconomic factors. Environ Health Perspect 1993; 101(suppl 2): 73-80.

11. Ali T, Sami N, Khuwaja A. Are unhygienic practices during the menstrual, partum and postpartum periods risk factors for secondary 
infertility? J Health Popul Nutr 2007; 25(2): 189-94.

12. Adetoro OO, Ebomoyi EW. The prevalence of infertility in a rural Nigerian community. Afr $\mathrm{J}$ Med Med Sci 1991; 20: 23-7.

13. Schrijvers D, Dupont A, Meheus A. Prevalence and type of infertility in Gabon. Ann Soc Belge Med Trop 1991; 71: 317-23.

14. Maheshwari A, Hamilton M, Bhattacharya S. Effect of female age on the diagnostic categories of infertility. Hum Reprod 2008; 23(3): 538-42.

15. Momtaz H, Flora MS, Shirin S. Factors associated with secondary infertility. Ibrahim Med Coll J $2011 ; 5(1)$ : 17-21.

16. Anwar BR, Fatima P, Afza N, Begum N, Kulsum SU, Parveen S. Aetiological factors of infertility: a study done in Bangabandhu Sheikh Mujib Medical University (BSMMU) - a tertiary level hospital in Bangladesh. J Dhaka Med Coll 2012; 21(2): 152-5.

17. Malekshah AK, Moghaddam AE, Moslemizadeh N, Peivandi S, Barzegarnejad A, Musanejad N, et al. Infertility in Mazandaran province - north of Iran: an etiological study. Iranian J Reprod Med 2011; 9(1): 21-4.
18. Philippov OS, Radionchenko AA, Bolotova VP, Voronovskaya NI, Potemkina TV. Estimation of the prevalence and causes of infertility in western Siberia. Bull World Health Organ 1998; 76: 1837 .

19. Ikechebelu JI, Adinma JIB, Orie EF, Ikegwuonu SO. High prevalence of male infertility in southeastern Nigeria. J Obstet Gynaecol 2003; 23(6): 657-9.

20. Bayasgalan G, Naranbat D, Tsedmaa B, Tsogmaa B, Sukhee D, Amarjargal O, et al. Clinical patterns and major causes of infertility in Mongolia. J Obstet Gynaecol Res 2004; 30(5): 386-93.

21. Fatima P, Chowdhury TA. Semen Parameters of male partners of couples attending infertility clinic. Bangladesh J Obstet Gynaecol 2001; 16(2): 60-3.

22. Pasqualotto FF, Locambo CV, Athayde KS, Arap S. Measuring male infertility: epidemiological aspects. Rev Hosp Clin Fac Med Sao Paulo 2003; 58(3): 173-8.

23. Maureen P. Occupational reproductive hazards. Lancet 1997; 349: 1385-8.

24. Papreen N, Sharma A, Sabin K, Begum L, Ahsan SK, Baqui AH. Living with infertility: experiences among urban slum populations in Bangladesh. Reprod Health Matters 2000; 8(15): 33-44. 